\section{Legal Issues in Human Reproduction}

Edited by Sheila McLean, 238 pages, Aldershot, $£ 29.50 \mathrm{hb}, £ 14.95 \mathrm{pb}$, Gower, 1989

This collection comprises nine essays: Michael Kirby points to the lacuna between the advances of medical technology and contemporary family law; Douglas Cusine gives a number of thumbnail sketches of some key issues; Ken Mason subjects abortion legislation to critical review; Bernard Dickens shows the inadequacy of developing tort law as a policy to affect the incidence of abortion; David Meyers compares US and UK precedents in the selective nontreatment of handicapped infants; Christopher Heginbotham challenges the claim that the sterilisation of a noncompetent minor or adult will never be in the person's best interests; Michael Freeman analyses arguments against surrogacy, arguing that the principal objection to it - that it exploits or dehumanises women - cannot be sustained; Rebecca Cook assesses, in the context of maternal mortality rates, the task of establishing and enforcing a legally constituted human right to women's reproductive health; and Sheila McLean concludes the collection by highlighting a paradox: what she sees as peripheral issues - such as the techniques medically selected for terminating pregnancies, viability, embryo experiments, fetal 'rights', sexual behaviour and sexual preference - have circumvented the real moral debate about the rights of those who have legitimate interests in contraception, pregnancy, childbirth and access to modern reproductive technology.

The contributors are mostly from the legal professions, or the contributors' professional work has demanded familiarity with legal practice and process. One of the book's most useful features is the overview which the contributors give of legal responses to specific disputes concerning people's reproductive capacities. For example, Dickens provides an admirably clear and succinct account of the US system of differentiating claims for wrongful pregnancy, wrongful conception, wrongful birth, wrongful life and dissatisfied life. Another good feature is that the contributors go beyond the niceties of legal argument to address the practical matter of realisable legal or institutional reforms, or at least to indicate the moral stance which they think should inform the direction those reforms should take.

Each contribution can be read as a self-contained essay. But there are several recurrent themes in the book as a whole. In this respect, one surmises that, pace the disclaimers in her introduction, the Editor must have had a principle of selection other than her intention merely to sample the various interests in the field. Similarly, whilst one sympathises with the Editor's reluctance to impose a party line on the contributors, her disappointingly brief introduction misses the opportunity to make connections between the chapters. Here are two examples of themes linking contributions. First, international comparisons made within chapters raise the wider issue of whether some jurisdictions are more suited than others to addressing the implications of medical advances, in particular the implementation of the type of moral rights which McLean herself wants to see retrieved from the margins of the debate. Secondly, several contributors remark on the peculiar position of women in the area of reproductive rights. Heginbotham, for example, notes the typical assumption, in disputes about the sterilisation of people with mental handicaps, that it is women, not men, who are to be sterilised. From this observation through the chapters by Freeman, Cook and McLean, the theme of what might be called the gendered nature of reproductive rights recurs more and more explicitly. To conclude, it would be a pity if readers attended only to chapters on topics they are already interested in, rather than treating the collection as a whole, but there is a risk that they will read the book in this way.

\section{ELIZABETH KINGDOM \\ Department of Sociology, Social Policy and Social Work Studies \\ University of Liverpool}

\section{Hare and Critics: Essays on Moral Thinking}

Edited by D Seanor and N Fotion, viii + 307 pages, Oxford, $£ 30.00$, Clarendon Press, 1988

This book is a collection of essays by very well known philosophers written in criticism of R M Hare's book, Moral Thinking, with detailed replies to the critics by Professor Hare himself.

Hare's thought has shown a remarkable consistency over the years, as W D Hudson explains in his masterly summary of it in this volume. Hare's basic idea is that moral judgements are, by their very nature, prescriptive and universalisable. The thesis that they are prescriptive embodies two claims: that they neither state facts nor are logically entailed by any facts, and that anyone who sincerely assents to a moral judgement is prepared to accept the imperative that it be acted on - actually act on it himself, if he is in the relevant situation. The thesis that they are universalisable entails that any reason adduced in support of a moral judgement implies a universal principle. A moral decision requires the agent to put himself in the place of each of those affected by possible actions (universalisability) and consider from that standpoint what he would be willing to prescribe (prescriptivity); his eventual prescription emerges from a sort of weighing-up of the tota satisfactions arising from each of the possible courses of action. Hare? system thus seems to provide a kind formal foundation for utilitarianism, and in Moral Thinking he develops the utilitarian aspect of his work by introducing a distinction between intuitive and critical levels of moral thinking. This is related to that commonly drawn between act and rule utilitarianism, and Hare believes it enables him to meet many of the usual criticisms of utilitarianism.

It is easy to see why Hare's work continues to fascinate (one might almost say obsess) other moral philosophers. Starting from minimal foundations, concerning what is necessarily involved in making moral judgements at all, he claims to be able to derive very powerful $D$ arguments in favour of substantive moral conclusions, and thus to defend $\mathrm{N}$ morality as a rational and in a sense $\sigma$ objective activity which yet does not $N$ require the existence of any kind of $N$ moral fact or any agreed moral starting $\sigma$ points. There have always been numerous critics to attack both Hare's account of what moral judgement is and $\mathbb{E}$ the conclusions which he draws from? this account, and the essays in this book, which are trenchant and lucid, are a formidable addition to the genre. Hare replies with his customary unrepentant precision.

This collection would be enjoyed by anyone interested in modern academic 